\title{
Associations between the concentrations of CD68, TGF- $\beta 1$, renal injury index and prognosis in glomerular diseases
}

\author{
JINGSHU SUN, LIHAI HAO and HONGBO SHI \\ Department of Nephrology, Weifang People's Hospital, Weifang, Shandong 261041, P.R. China
}

Received June 7, 2019; Accepted May 27, 2020

DOI: $10.3892 /$ etm.2020.9184

\begin{abstract}
The present study aimed to investigate the association between the concentrations of CD68, TGF- $\beta 1$, renal injury index and prognosis in glomerular diseases. Altogether 218 patients with glomerular diseases admitted to Weifang People's Hospital from January, 2014 to March, 2017 were used as the study group. A total of 100 healthy individuals who visited Weifang People's Hospital for a physical examination during the same time period were used as the control group. The levels of CD68 in peripheral blood obtained from the 2 groups of subjects were detected by flow cytometry, and the expression of TGF- $\beta 1$ in serum was detected by enzyme-linked immunosorbent assay (ELISA). The concentrations of CD68 and TGF- $\beta 1$ between the 2 groups were compared. The correlation between the concentrations of CD68, TGF- $\beta 1$ and renal injury indexes in the study group was analyzed, as well as prognostic significance. The diagnostic value of CD68 and TGF- $\beta 1$ in patients with glomerular disease was analyzed using a ROC curve, and the recovery of the patients was observed. The serum concentrations of CD68 and TGF- $\beta 1$ in the study group were higher than those in the control group $(\mathrm{P}<0.05)$. The concentrations of CD68 and TGF- $\beta 1$ in the study group positively correlated with the renal injury indexes, such as blood urea nitrogen (BUN), serum creatinine (SCR), uric acid (UA) and the 24-h urinary protein quantity $(\mathrm{P}<0.05)$. ROC curve analysis revealed that the area under the curve of CD68 and TGF- $\beta 1$ as regards the diagnostic value in patients with glomerular disease was 0.808 and 0.738 , respectively, while the area under the combined detection curve was 0.866. Multivariate unconditional logistic regression analysis revealed that the clinical classification and the concentrations of CD68 and TGF- $\beta 1$ were independent prognostic factors in the study group. On the whole, the findings of the present study demonstrate that clinical classification, and the CD68 and TGF- $\beta 1$ concentrations are independent prognostic factors
\end{abstract}

Correspondence to: Dr Hongbo Shi, Department of Nephrology, Weifang People's Hospital, 151 Guangwen Street, Kuiwen, Weifang, Shandong 261041, P.R. China

E-mail: hpte11@163.com

Key words: renal glomerular disease, CD68, TGF- $\beta 1$, diagnosis for patients with glomerular disease. CD68 and TGF- $\beta 1$ have certain value in the diagnosis of glomerular diseases, and may thus be used as predictors of the diagnosis and recovery of glomerular disease.

\section{Introduction}

Glomerular disease affects both kidneys (1), and is mainly caused by primary glomerulopathy (2). Glomerular disease is the main cause of chronic renal failure, which requires dialysis or renal transplantation to improve the quality of life in patients with end-stage renal disease (3). At present, renal biopsy is the main strategy used to evaluate glomerulopathy (4). In very few and specific cases, patients with poor renal function and a lower platelet count suffer from severe serious bleeding following renal biopsy (5), and in such cases, renal biopsies are not suitable. Thus, the identification of a novel method with which to diagnose glomerular disease more conveniently and at an earlier stage is urgently required in clinical practice, which may provide information for clinical treatment. The current developments in genomics, epigenetics, transcriptomics, proteomics and metabolomics suggest that the introduction of novel technologies mat aid in the identification of novel biomarkers for kidney disease; the diagnosis of chronic kidney disease is usually based on the levels of blood urea and serum creatinine $(\mathrm{sCr})$; however, it has been proven that $\mathrm{sCr}$ lacks a high predictive value (6). In the study by Ling et al (7), urinary CD80 levels were used as non-invasive diagnostic biomarkers, which is important for the early diagnosis of nephrotic syndrome, suggesting that a better biological indicator could be found.

Monocytes/macrophages are defense cells which originate in mesoblasts and play important roles in immune and non-immune functions (8). When glomerulonephritis occurs, mononuclear/macrophage infiltration can be found in renal tissue (9), which reflects the degree of glomerular disease to a certain extent. CD68 is a cell-pulp glycoprotein with a relative molecular mass of 110,000 , which is associated with lysosomal particles and is the most reliable marker for macrophages (10). The transforming growth factor- $\beta$ (TGF- $\beta$ ) plays an important role in the pathophysiological processes of tumor (11) and cardiovascular disease (12) in a group of newly discovered TGF- $\beta$ superfamily that regulate cell growth and differentiation. TGF- $\beta 1$ is an important cytokine in the process of glomerulosclerosis (13) and 
tubule fibrosis (14), which can be regarded as a marker of inflammation.

The aim of the present study was to determine whether the concentrations of CD68 and TGF- $\beta 1$ in patients with glomerular disease can be used as clinical diagnostic indexes for glomerular diseases, which may provide a reference for the diagnosis and treatment of glomerular diseases.

\section{Patients and methods}

General materials. A total of 218 patients with glomerulopathy diagnosed at Weifang People's Hospital from January, 2014 to March, 2017 were used as the study group, including 132 males and 86 females, aged 33 to 64 years. In addition, blood was collected from 100 healthy individuals who underwent a physical examination at the same hospital and during the same time period. These healthy individuals were enrolled as the control group, and included 66 males and 34 females, aged 25 to 65 years. The present study was approved by the Ethics Committee of Weifang People's Hospital, and all the research subjects have signed the informed consent forms.

Inclusion and exclusion criteria. The inclusion criteria were as follows: The diagnosis was made was in accordance with the criteria for the diagnosis of glomerular disease (15); patients were treated at Weifang People's Hospital, and were aged between 18 to 70 years; patients were to have had a primary school or higher education; patients who cooperated with the research protocol; patients had to be without any serious diseases in other organs. All subjects or their immediate families signed the informed consent forms.

The exclusion criteria were as follows: Death during treatment; patients with respiratory or blood system diseases; patients with mental diseases and speech dysfunction; pregnant or lactating women; patients who had recently been treated with immunosuppressive agents and hormone drugs.

Detection of CD68 and TGF- $\beta 1$ in serum. Peripheral blood samples were collected from the subjects in the 2 groups in vacuum blood collection tubes in the morning, and were separated into two parts. One part of the blood was separated by centrifugation at $1,505 \mathrm{x} \mathrm{g}$ at $4^{\circ} \mathrm{C}$ for $10 \mathrm{~min}$. The upper serum was put into the $-80^{\circ} \mathrm{C}$ refrigerator for testing. The level of serum TGF- $\beta 1$ was detected by ELISA in strict accordance with the kit instructions (SND-H035; Chuzhou Shinuoda Biological Technology Co., Ltd.).

The other part was for CD68 detection. Following the dilution of an equal volume of phosphate-buffered saline solution, peripheral blood mononuclear cells (PBMCs) were obtained by density gradient centrifugation using human lymphocyte separation solution. The concentration of the cells was adjusted to $2 \times 10^{6} / \mathrm{ml}$ with RPMI- 1640 medium (cat. no. CDLG-5404; ChunduBio). The cells were inoculated in a 24 -well culture plate and then added with the stimulant, phorbol myristate acetate $(50 \mu \mathrm{g} / \mathrm{l})$, ionomycin $(1 \mu \mathrm{mol} / \mathrm{l})$ and the protein transport inhibitor, monensin $(50 \mu \mathrm{g} / \mathrm{l})$. The mixture was mixed and cultured in a $5 \% \mathrm{CO}_{2}$ cell incubator at $37^{\circ} \mathrm{C}$ for $4 \mathrm{~h}$. The cells were collected and divided into experimental tubes and control tubes equally. This was followed by the addition of $4 \mu 1$ FITC-labeled mouse anti-human CD68 monoclonal antibody (bs-20402r; Bioss), incubation at $4^{\circ} \mathrm{C}$ in the dark for $30 \mathrm{~min}$, and washing twice with PBS. The fixative was maintained at room temperature for $20 \mathrm{~min}$, and then centrifuged at $1,505 \mathrm{x} \mathrm{g}$ at $4^{\circ} \mathrm{C}$. The supernatant was then discarded, and washed twice with PBS. Subsequently, $1 \mathrm{ml}$ of rupture agent (EY-24882; Shanghai Institute of Biotechnology Co., Ltd.) was added to each tube for cell puncturing to facilitate the entry of cytokine monoclonal antibody (Shanghai Qunji Biological Technology Co., Ltd., MAB11128) into the cells. Following centrifugation $1,505 \mathrm{x} \mathrm{g}$ at $4^{\circ} \mathrm{C}$ for $10 \mathrm{~min}$, the supernatant was discarded, and intracellular cytokine staining at $4^{\circ} \mathrm{C}$ for 30 min was performed. CD68-postivie cells were detected by flow cytometry (BD FACSAria ${ }^{\mathrm{TM}}$ III sorter; BD Biosciences).

Observation of renal injury index. The examination of renal injury indexes was observed in the 2 groups. The indexes of renal injury included blood urea nitrogen (BUN), serum creatinine (SCR), glycosylated albumin (GA), glycosylated hemoglobin (HbAlc) and 24-h urinary protein quantity.

Observation index. The clinical data of the patients were recorded and analyzed, including renal injury indicators, such as blood urea nitrogen (BUN), serum creatinine (SCR), uric acid (UA), 24-h urine protein quantity, white blood cell count (WBC) and platelet count (PC).

Statistical analysis. SPSS v24.0 software (Yuchuang Network Technology Co., Ltd.) was used to calculate all experimental results. Graphpad8 software (Softhead Inc.) was used to plot figures and examine the results again. The counting data were represented in the form of rate. The Chi-square test was used for comparison between groups. The measurement data are expressed as the means \pm standard deviation. The t-test was used for comparisons between groups. Repeated measures analysis of variance was used for comparisons of multiple time points in the group, followed by Bonferroni's correction. Correlation analysis was performed using Spearman's correlation analysis. A value of $\mathrm{P}<0.050$ was considered to indicate a statistically significant difference between groups.

\section{Results}

General characteristics of the 2 groups. No significant differences were observed in age, sex, BMI, medical history, marital status, smoking history and alcohol consumption history between the study group and the control group ( $\mathrm{P}>0.050)$, which proved that the 2 groups of patients were comparable (Table I).

Comparison of the CD68 and TGF- $\beta 1$ concentration in serum between the 2 groups. Compared with the control group, the expression of CD68 in the study group was significantly increased $(\mathrm{P}<0.05)$. The concentration of TGF- $\beta 1$ in the study group was $12.36 \pm 4.41 \mathrm{pg} / \mathrm{ml}$, which was higher than that in the control group $(9.25 \pm 3.56 \mathrm{pg} / \mathrm{ml})(\mathrm{P}<0.05$; Fig. 1).

Comparison of the renal injury index concentration between the 2 groups. The levels of BUN, SCR and UA and the 24-h urinary protein quantity in the study group were significantly higher than those in the control group $(\mathrm{P}<0.05$; Table II). 
Table I. Comparison of the clinical data.

\begin{tabular}{|c|c|c|c|c|}
\hline Index & Study group $(\mathrm{n}=218)$ & Control group $(\mathrm{n}=100)$ & $\chi^{2}$ or test & P-value \\
\hline Age (years) & $47.29 \pm 5.38$ & $46.71 \pm 6.17$ & 0.852 & 0.395 \\
\hline Sex, n $(\%)$ & & & 0.867 & 0.352 \\
\hline Male & $132(60.55)$ & $66(66.00)$ & & \\
\hline Female & $86(39.45)$ & $34(34.00)$ & & \\
\hline BMI $\left(\mathrm{kg} / \mathrm{m}^{2}\right)$ & $23.47 \pm 1.81$ & $23.34 \pm 1.93$ & 0.582 & 0.561 \\
\hline \multicolumn{5}{|l|}{ Medical history, n (\%) } \\
\hline Hypertension & $48(22.02)$ & $25(25.00)$ & 0.347 & 0.557 \\
\hline Diabetes mellitus & $45(20.64)$ & $19(19.00)$ & 0.009 & 0.927 \\
\hline Hyperlipemia & $37(16.97)$ & $17(17.00)$ & 0.162 & 0.688 \\
\hline Marital status, n (\%) & & & 0.301 & 0.583 \\
\hline Married & $173(79.36)$ & $82(82.00)$ & & \\
\hline Unmarried & $45(20.64)$ & $18(18.00)$ & & \\
\hline Smoking history, n (\%) & & & 0.284 & 0.594 \\
\hline Yes & $129(59.17)$ & $56(56.00)$ & & \\
\hline No & $89(40.83)$ & $44(44.00)$ & & \\
\hline Alcohol consumption, n (\%) & & & 0.341 & 0.559 \\
\hline Yes & $121(55.50)$ & $59(59.00)$ & & \\
\hline No & $97(44.50)$ & $41(41.00)$ & & \\
\hline Leukocytes $\left.1 \times 10^{9} / 1\right)$ & $12.84 \pm 4.46$ & $5.35 \pm 1.38$ & 16.421 & $<0.001$ \\
\hline Blood platelet count $\left(1 \times 10^{9} / 1\right)$ & $225.17 \pm 66.94$ & $213.38 \pm 67.89$ & 1.452 & 0.147 \\
\hline
\end{tabular}
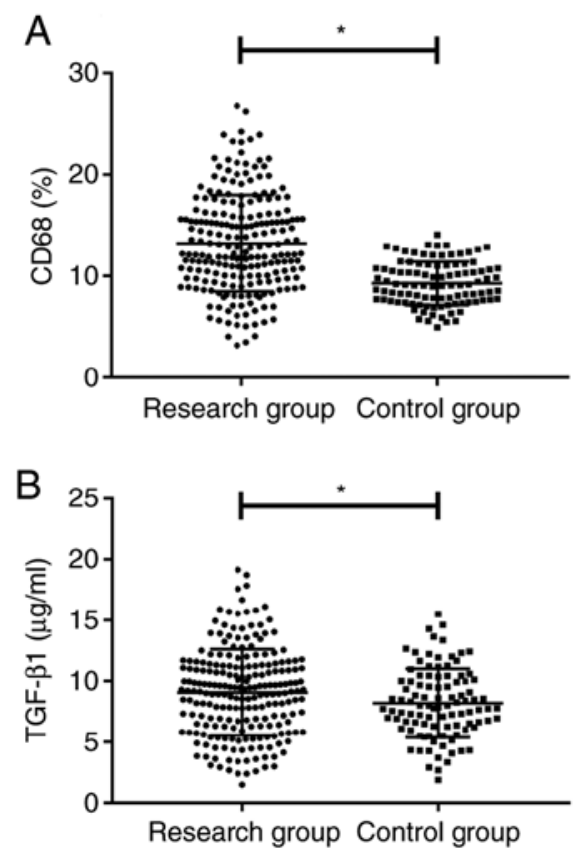

Figure 1. Comparison of CD68 and the TGF- $\beta 1$ concentration in serum between the 2 groups. (A) Comparison of the concentration of CD68; ${ }^{*} \mathrm{P}<0.05$. (B) Comparison of the concentration of TGF- $\beta 1{ }^{*} \mathrm{P}<0.05$.

Correlation analysis of $C D 68$ and TGF- $\beta 1$ with renal injury indexes in the study group. The serum levels of CD68 in the study group positively correlated with the BUN $(r=0.647$; 95\% CI, 0.56-0.72; $\left.\mathrm{R}^{2}=0.419 ; \mathrm{P}<0.001\right)$, SCR ( $\mathrm{r}=0.605$; 95\% CI, 0.51-0.68; $\left.\mathrm{R}^{2}=0.367 ; \mathrm{P}<0.001\right)$ and UA $(\mathrm{r}=0.497$;
95\% CI, 0.39-0.59; $\left.\mathrm{R}^{2}=0.247 ; \mathrm{P}<0.001\right)$ levels, and with the 24-h urinary protein quantity $(\mathrm{r}=0.697 ; 95 \% \mathrm{CI}, 0.62-0.76$; $\mathrm{R}^{2}=0.486$; $\mathrm{P}<0.001$; Fig. 2).

The level of TGF- $\beta 1$ in serum of the study group also positively correlated with the BUN ( $r=0.376,95 \%$ CI, 0.26-0.48; $\left.\mathrm{R}^{2}=0.142 ; \mathrm{P}<0.001\right), \mathrm{SCR}\left(\mathrm{r}=0.513 ; 95 \% \mathrm{CI}, 0.41-0.60 ; \mathrm{R}^{2}=0.263\right.$; $\mathrm{P}<0.001)$ and UA $\left(\mathrm{r}=0.534 ; 95 \% \mathrm{CI}, 0.43-0.62 ; \mathrm{R}^{2}=0.285\right.$; $\mathrm{P}<0.001)$ levels, and with the 24 -h urinary protein quantity $\left(r=0.379 ; 95 \%\right.$ CI, 0.26-0.49; $\mathrm{R}^{2}=0.144 ; \mathrm{P}<0.001$; Fig. 3).

Diagnostic efficacy of CD68 and TGF- $\beta 1$ on glomerular diseases. ROC curve analysis revealed that the area under the curve of CD68 was 0.808 , and the cut-off value was 8.606 , with a sensitivity of $63.76 \%$ and specificity of $89.00 \%$. The area under the curve of TGF- $\beta 1$ was 0.738 , and the cut-off value was $9.881 \mathrm{pg} / \mathrm{ml}$, with a sensitivity of $74.31 \%$ and specificity of $62.00 \%$. The area under the curve of CD68 and TGF- $\beta 1$ combination was 0.866 , and the cut-off value was 0.308 , with a sensitivity of $76.15 \%$ and specificity of $84.00 \%$ (Fig. 4).

Univariate alysis of the association between patient characteristics and renal function. According to the remission of renal function, the patients were divided into the renal function remission group (139 cases, 63.76\%) and renal function non-remission group (79 cases, 36.24\%). The clinical data of the 2 groups were collected and analyzed using by univariate analysis using the Chi-squared test or t-test. It was found that there was no difference in sex, BMI, medical history, smoking history and alcohol consumption history between the 2 groups $(\mathrm{P}>0.05)$; however, a significant 
Table II. Comparison of the concentrations of renal injury indexes between the two groups.

\begin{tabular}{lcrrr}
\hline Index & Study group $(\mathrm{n}=218)$ & Control group $(\mathrm{n}=100)$ & $\mathrm{t}$ value & P-value \\
\hline BUN $(\mathrm{mmol} / \mathrm{l})$ & $13.39 \pm 3.52$ & $4.36 \pm 2.48$ & 23.141 & $<0.001$ \\
SCR $(\mu \mathrm{mmol} / \mathrm{l})$ & $521.49 \pm 24.38$ & $76.29 \pm 25.23$ & 149.521 & $<0.001$ \\
UA $(\mu \mathrm{mol} / \mathrm{l})$ & $481.46 \pm 31.85$ & $279.39 \pm 29.49$ & 53.753 & $<0.001$ \\
24-h urinary protein quantity $(\mathrm{mg} / 24 \mathrm{~h})$ & $190.38 \pm 19.48$ & $76.39 \pm 15.49$ & 51.512 & $<0.001$ \\
\hline
\end{tabular}
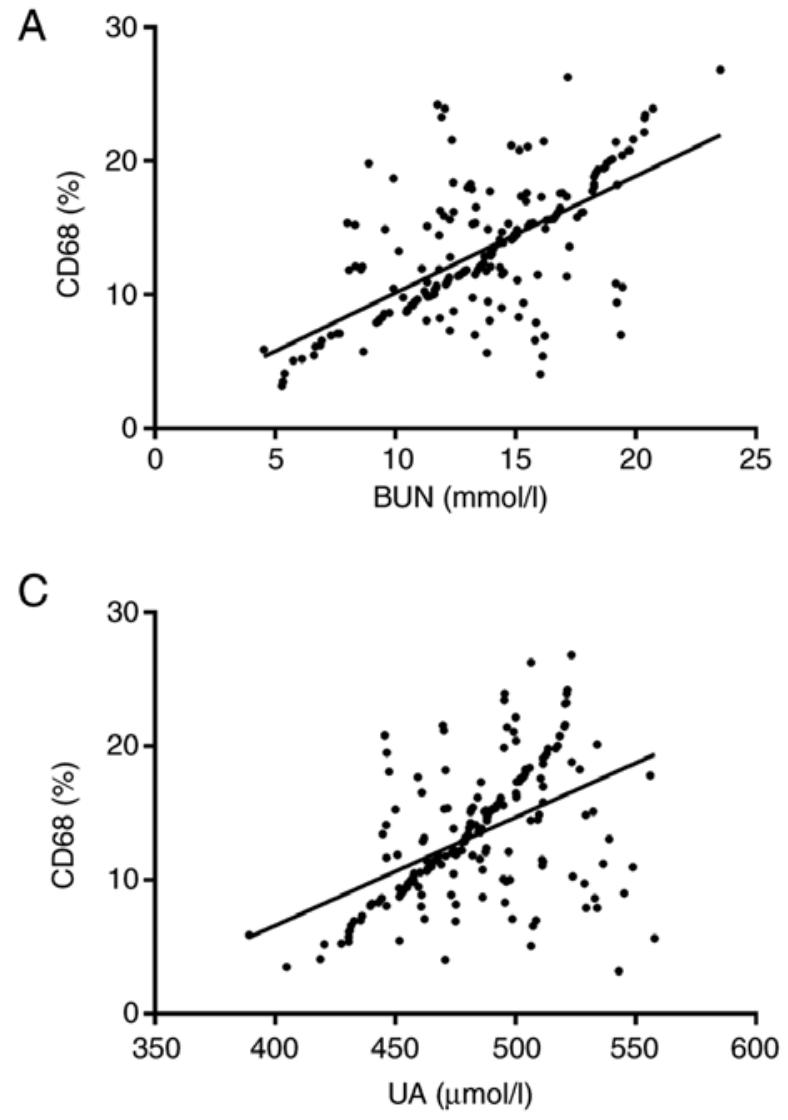

B

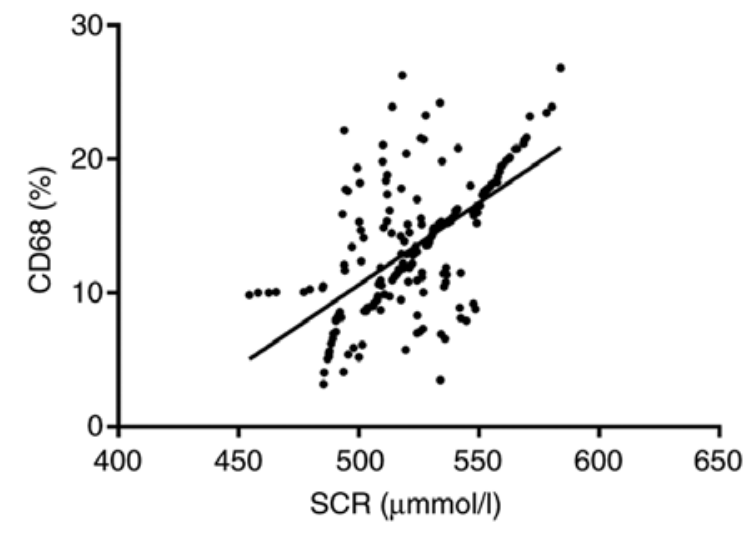

D

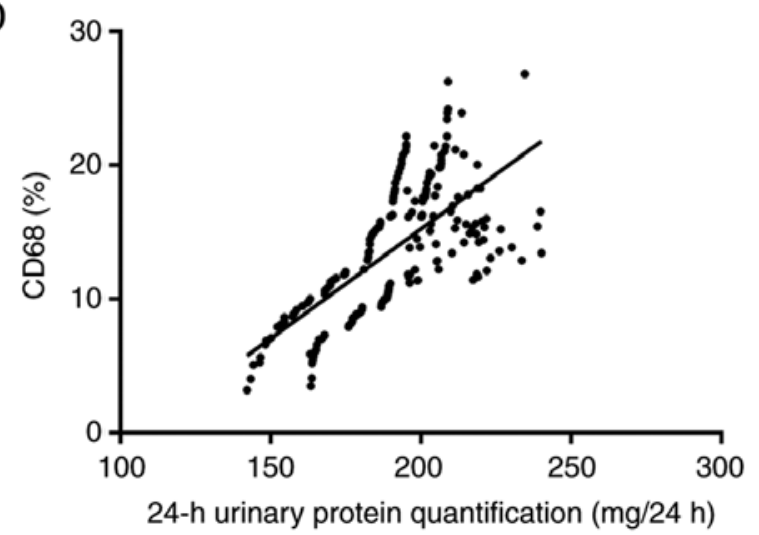

Figure 2. Correlation analysis of CD68 with renal injury indexes in the study group. (A) Correlation analysis of CD68 level and BUN level in the study group. (B) Correlation analysis of CD68 and SCR level in the study group. (C) Correlation analysis of CD68 level and UA level in the study group. (D) Correlation analysis of CD68 level and 24-h urinary protein quantity in the study group. BUN, blood urea nitrogen; SCR, serum creatinine; UA, uric acid.

difference was observed in clinical classification, and in the levels of CD68 and TGF- $\beta 1$ between the 2 groups $(\mathrm{P}<0.05$; Table III).

Multivariate analysis of the prognosis of renal function. The indicators with differences in univariate analysis into the assignment (the assignment information is presented in Table IV). The results of multivariate logistic regression analysis with LR revealed that oliguria, clinical classification, and the CD68 and TGF- $\beta 1$ levels were prognostic factors of renal function in patients $(\mathrm{P}<0.05$; Table $\mathrm{V})$.

\section{Discussion}

Renal glomerular disease leads to earlier and severer damage to glomerular function before it affects renal tubular function (16). Glomerular disease has a severe impact on the quality of life of patients, and poses a heavy burden on the health care system (17). It is generally considered that the immune mechanism is the initiating mechanism of glomerulopathy. On this basis, inflammatory mediators (18) and complement activation (19) function together to induce the occurrence and development of the disease. At present, the main methods of the clinical diagnosis of glomerulopathy are the observation of the clinical manifestations of patients and renal biopsy. However, renal biopsy can cause side-effects, such as pain and anxiety (20); thus, it is crucial to evaluate the degree of renal injury by evaluating the process of renal disease more conveniently and quickly.

The CD68 molecule is an important surface marker of macrophages, which is often used for macrophage identification and functional analysis (21). At present, it has been confirmed that CD68 is closely related to non-small cell lung cancer (22) and colorectal adenoma (23); however, 

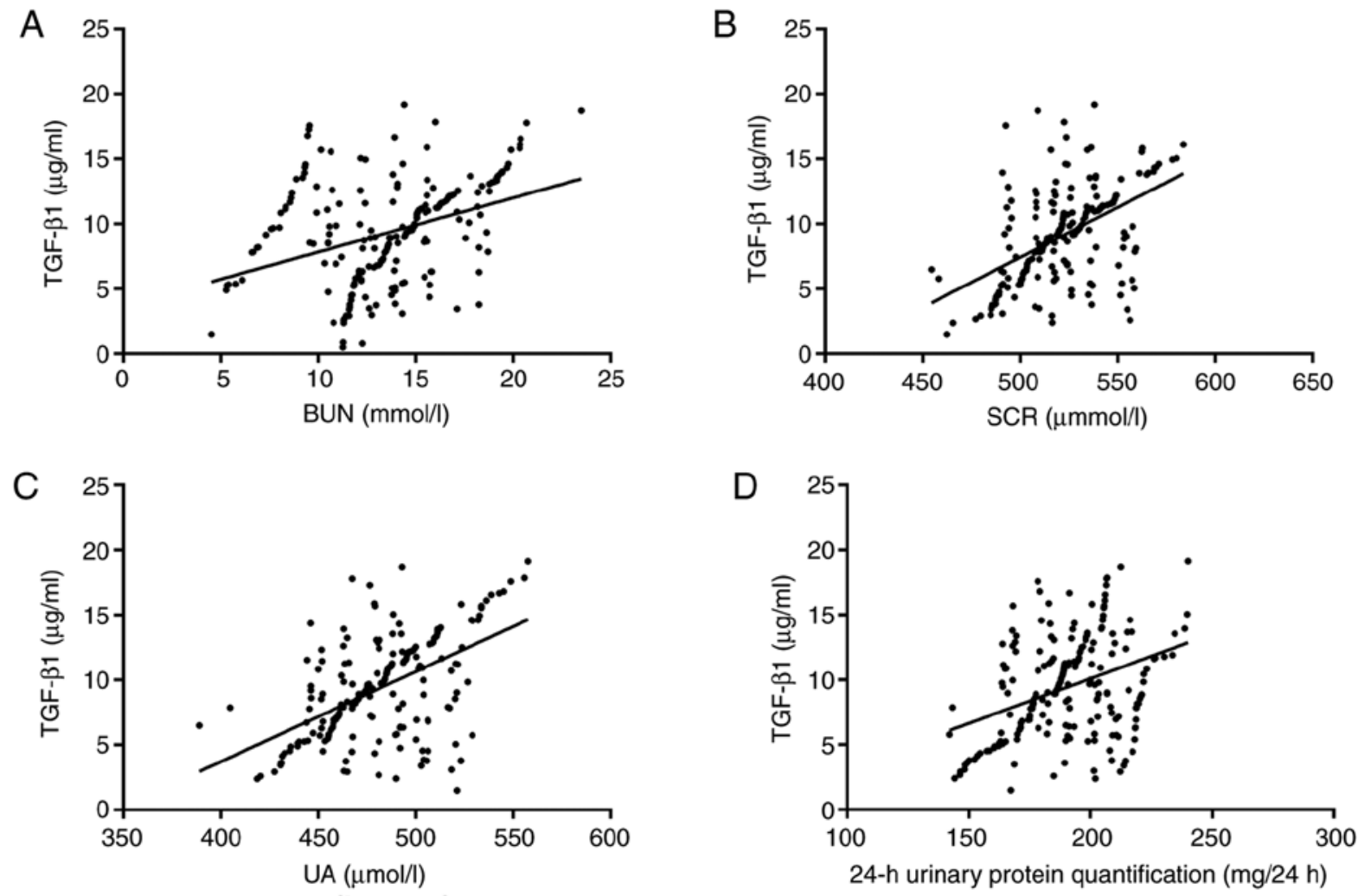

Figure 3. Correlation analysis of the TGF- $\beta 1$ level with renal injury indexes in the study group. (A) Correlation analysis of the TGF- $\beta 1$ level and the BUN level in the study group. (B) Correlation analysis of the TGF- $\beta 1$ level and the SCR level in the study group. (C) Correlation analysis of the TGF- $\beta 1$ level and the UA level in the study group. (D) Correlation analysis of the TGF- $\beta 1$ level and the 24 -h urinary protein quantity in the study group. BUN, blood urea nitrogen; SCR, serum creatinine; UA, uric acid.

A

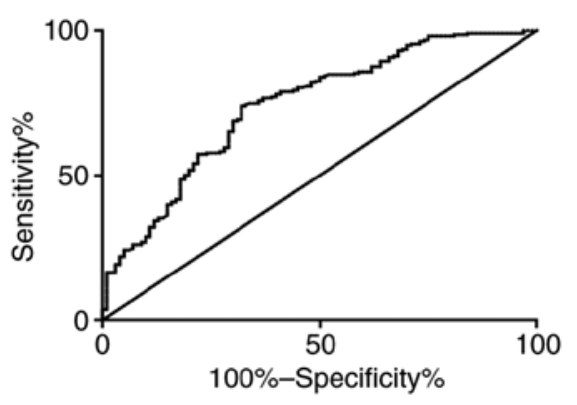

B

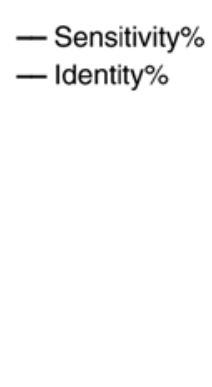

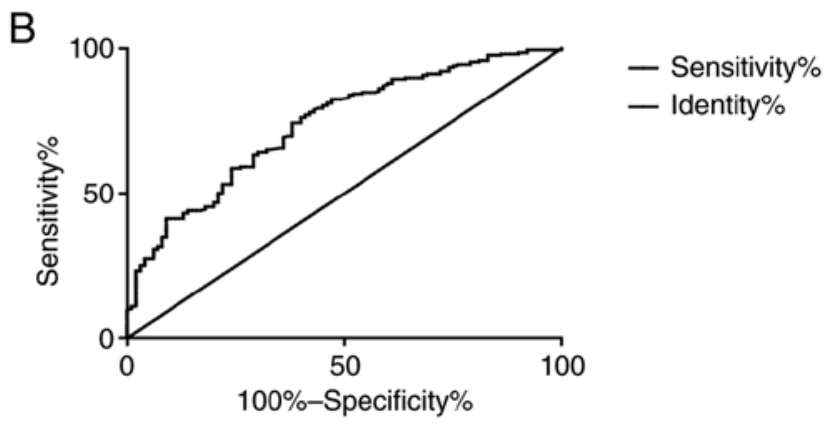

- Sensitivity\%

- Identity\%

Figure 4. (A) ROC curve of CD68 level in the diagnosis of glomerular disease. (B) ROC curve of the TGF- $\beta 1$ level in the diagnosis of glomerular disease. (C) ROC curve of CD68 and TGF- $\beta 1$ in combination for the diagnosis of glomerular disease.

there is a lack of research on the correlation between CD68 and glomerulopathy. In the present study, the concentration of CD68 in the serum of the study group and the control group revealed that the concentration of CD68 in the study group was significantly increased and positively correlated with the concentration of renal injury indexes, 
Table III. Univariate analysis.

\begin{tabular}{|c|c|c|c|c|}
\hline Factor & $\begin{array}{l}\text { Renal function remission } \\
\text { group }(\mathrm{n}=139)\end{array}$ & $\begin{array}{l}\text { Renal function non-remission } \\
\text { group }(\mathrm{n}=79)\end{array}$ & $\chi^{2}$ or test & $\mathrm{P}$-value \\
\hline Age (years), n (\%) & & & 0.156 & 0.693 \\
\hline$\geq 55$ & $86(61.87)$ & $51(64.55)$ & & \\
\hline$\geq 55$ & $53(38.13)$ & $28(35.44)$ & & \\
\hline Sex, n (\%) & & & 0.002 & 0.962 \\
\hline Male & $84(60.43)$ & $48(60.76)$ & & \\
\hline Female & $55(39.57)$ & $31(39.24)$ & & \\
\hline $\operatorname{BMI}\left(\mathrm{kg} / \mathrm{m}^{2}\right)$ & $23.55 \pm 1.34$ & $23.46 \pm 1.50$ & 0.456 & 0.648 \\
\hline \multicolumn{5}{|l|}{ Medical history, n (\%) } \\
\hline Hypertension & $25(12.85)$ & $23(29.11)$ & 3.633 & 0.057 \\
\hline Diabetes mellitus & $29(20.86)$ & $16(20.25)$ & 0.011 & 0.915 \\
\hline Hyperlipemia & $24(17.26)$ & $13(16.46)$ & 0.023 & 0.878 \\
\hline Smoking history, $\mathrm{n}(\%)$ & & & 1.486 & 0.223 \\
\hline Yes & $78(56.12)$ & $51(64.56)$ & & \\
\hline No & $61(43.88)$ & $28(35.44)$ & & \\
\hline Alcohol consumption, n (\%) & & & 1.385 & 0.239 \\
\hline Yes & $73(52.52)$ & $48(60.75)$ & & \\
\hline No & $66(47.48)$ & $31(39.25)$ & & \\
\hline Oliguresis & $15(10.79)$ & $48(60.75)$ & 61.213 & $<0.001$ \\
\hline Clinical classification & & & 44.321 & $<0.001$ \\
\hline Glomerular nephritis & $61(43.89)$ & $12(15.99)$ & & \\
\hline Hematuria or proteinuria & $49(5.35)$ & $15(18.99)$ & & \\
\hline Nephrotic syndrome & $29(2086)$ & $52(65.82)$ & & \\
\hline Leukocyte $\left(1 \times 10^{9} / 1\right)$ & $12.84 \pm 2.31$ & $13.41 \pm 3.19$ & 1.520 & 0.130 \\
\hline Blood platelet count $\left(1 \times 10^{9} / 1\right)$ & $219.57 \pm 56.94$ & $233.39 \pm 49.33$ & 1.806 & 0.07 \\
\hline CD68 & $7.06 \pm 1.48$ & $8.39 \pm 2.70$ & 4.701 & $<0.001$ \\
\hline TGF- $\beta 1$ & $11.09 \pm 3.81$ & $12.78 \pm 3.25$ & 3.315 & $<0.001$ \\
\hline
\end{tabular}

Table IV. Assignment of factors.

\begin{tabular}{ll}
\hline Factor & \multicolumn{1}{c}{ Assignment } \\
\hline Oliguresis & Yes, $1 ;$ no, 0 \\
Clinical classification & Glomerular nephritis, 1; hematuria or proteinuria, 2; nephrotic syndrome, 3 \\
CD68 & Data are continuous variables using the original data analysis \\
TGF- $\beta 1$ & Data are continuous variables using the original data analysis \\
Remission of renal function & Remission, 1; non-remission, 0
\end{tabular}

suggesting that CD68 may be related to the occurrence of glomerular diseases. Dias et al found that CD68 was associated with the progression of chronic kidney disease in 50 patients with proliferative LN by immunohistochemical analysis (24). Guillén-Gómez et al found that a large number of CD68-positive cells in the kidneys were negatively associated with long-term renal function (25), which was consistent with the results of the present study. TGF- $\beta$ is a $25 \mathrm{kDa}$ homodimer prototype of the protein family that regulate cell growth and differentiation, which can stimulate and inhibit cell growth, and is considered to be the main switch in the pathogenesis of organ fibrosis (26). Renal fibrosis is a common pathological feature of almost all types of chronic renal diseases, which is closely related to the decline of renal function (27). Renal fibrosis is mainly caused by the formation of tissue scar by activating TGF- $\beta 1 /$ Smads signaling pathway (28). The association between TGF- $\beta 1$ and the process of glomerular disease is not yet clear. In the present study, the concentration of TGF- $\beta 1$ in patients with glomerular disease was significantly higher 
Table V. Multifactor analysis.

95\% CI of $\operatorname{Exp}(\mathrm{B})$

\begin{tabular}{lccccccr} 
& & & & & & \multicolumn{2}{c}{$95 \%$ CI of Exp (B) } \\
\cline { 5 - 8 } Variable & $\mathrm{B}$ & $\mathrm{SE}$ & Wals & Sig. & Exp (B) & Lower limit & Upper limit \\
\hline $\begin{array}{l}\text { Oliguresis } \\
\text { Clinical classification }\end{array}$ & 0.714 & 0.831 & 0.739 & 0.389 & 2.044 & 1.403 & 4.435 \\
Glomerular nephritis & 1.863 & 0.800 & 5.414 & 0.020 & 6.436 & 2.341 & 9.848 \\
Hematuria or proteinuria & 2.013 & 0.933 & 4.62 & 0.031 & 7.491 & 4.184 & 12.826 \\
Nephrotic syndrome & 1.913 & 0.542 & 11.693 & 0.002 & 6.781 & 5.261 & 9.327 \\
CD68 & 1.497 & 0.560 & 4.862 & 0.024 & 3.475 & 1.140 & 5.536 \\
TGF- $\beta 1$ & 1.512 & 0.682 & 4.886 & 0.025 & 2.541 & 1.300 & 5.171 \\
\hline
\end{tabular}

than that in healthy individuals and positively correlated with the concentration of renal injury indexes, suggesting that TGF- $\beta 1$ may be a marker for determining the process of glomerular diseases. The study by Fukuda et al (29) demonstrated that urinary podocytes and TGF- $\beta 1$ mRNA expression may be used as markers for the progression and treatment of anti-glomerular basement membrane nephritis, which to a certain extent supports the present experimental results. In the previous study by Ostermann et al (30), serum creatinine and urine output were only signs of excretion function, and the abnormal performance needed to be explained in the clinical context. In the case of slow changes in creatinine and urine values, misleading or inaccurate interpretation occurs, lacking sufficient sensitivity, and other tools are required to diagnose acute kidney injury. As for the complex pathological mechanisms involved in the development and progression of glomerular disease, a combination of markers is required to reflect all types of changes during this disease process. In the present study, through ROC curve analysis, it was found that the area under the CD68 curve was 0.808 , and the area under the TGF- $\beta 1$ curve was 0.738 . The area under the CD68 and TGF- $\beta 1$ combination curve was 0.866 , and the cut-off value was 0.308 , with a sensitivity of $76.15 \%$ and specificity of $84.00 \%$. That indicates that the CD68 and TGF- $\beta 1$ combination can be used a biomarker for the diagnosis of glomerular disease. At the same time, according to the remission of renal function, the patients were divided into the remission group and non-remission group. The clinical classification, and CD68 and TGF- $\beta 1$ levels were shown to be independent risk factors that affect the response of renal function through multivariate logistic regression analysis, which suggests that the concentrations of CD68 and TGF- $\beta 1$ can be used as predictive indexes for renal function remission in patients with glomerular diseases. Mehta et al (31), analyzed the association between the plasma TGF- $\beta$ level and chronic kidney disease in the elderly by analyzing the data of 1,722 elderly subjects, and evaluated whether the baseline TGF- $\beta$ level could predict eGFR. It was found that the level of TGF- $\beta$ was independently associated with a lower eGFR in cross-section analysis, but not with albuminuria.

In the present study, the subjects were selected strictly according to the inclusion and exclusion criteria. No significant differences were found in sex, age, BMI and medical history between the study group and the control group, which ensured the rigor and reliability of the study. In the present study, the number of samples was small, and in the analysis of the prognosis of the patients with glomerular disease, the follow-up was not performed on the patients. The long-term prognosis was unknown, which is a limitation to the present study. In future research, it is necessary to extend the research time and expand the sample size.

In conclusion, the present study demonstrates that the increased concentrations of CD68 and TGF- $\beta 1$ in patients with glomerular disease are positively correlated with the indicators of renal injury, and are expected to become clinical diagnostic indicators of glomerular disease.

\section{Acknowledgements}

Not applicable.

\section{Funding}

No funding was received.

\section{Availability of data and materials}

The datasets used and/or analyzed during the present study are available from the corresponding author on reasonable request.

\section{Authors' contributions}

JS and LH were responsible for ELISA. JS and LH analyzed and interpreted the patient data. HS assisted with the statistical analysis. JS wrote the manuscript. All authors read and approved the final manuscript.

\section{Ethics approval and consent to participate}

The study was approved by the Ethics Committee of Weifang People's Hospital. Patients who participated in this research, signed the informed consent and had complete clinical data. Signed written informed consents were obtained from the patients and/or guardians. 


\section{Patient consent for publication}

Not applicable.

\section{Competing interests}

The authors declare that they have no competing interests.

\section{References}

1. Herrera-Caceres JO, Finelli A and Jewett MAS: Renal tumor biopsy: Indicators, technique, safety, accuracy results, and impact on treatment decision management. World J Urol 37: 437-443, 2019.

2. Zhu P, Zhou FD, Wang SX, Zhao MH and Wang HY: Increasing frequency of idiopathic membranous nephropathy in primary glomerular disease: A 10 -yearrenal biopsy study from a single Chinese nephrology centre. Nephrology (Carlton) 20: 560-566, 2015

3. Thakkar UG, Vanikar AV and Trivedi HL: Stem cell therapy: An emerging modality in glomerular diseases. Cytotherapy 19: 333-348, 2017.

4. Lees JS, McQuarrie EP and Mackinnon B: Renal biopsy: It is time for pragmatism and consensus. Clin Kidney J 11: 605-609, 2018.

5. Xu DM, Chen M, Zhou FD and Zhao MH: Risk Factors for severe bleeding complications in percutaneous renal biopsy. Am J Med Sci 353: 230-235, 2017.

6. Moledina DG, Hall IE, Thiessen-Philbrook H, Reese PP Weng FL, Schröppel B, Doshi MD, Wilson FP, Coca SG and Parikh CR: Performance of serum creatinine and kidney injury biomarkers for diagnosing histologic acute tubular injury. Am J Kidney Dis 70: 807-816, 2017.

7. Ling C, Liu X, Shen Y, Chen Z, Fan J, Jiang Y and Meng Q: Urinary CD80 levels as a diagnostic biomarker of minimal change disease. Pediatr Nephrol 30: 309-316, 2015.

8. Lee AH, Ledderose C, Li X, Slubowski CJ, Sueyoshi K, Staudenmaier L, Bao Y, Zhang J and Junger WG: Adenosine triphosphate release is required for toll-like receptor-induced monocyte/macrophage activation, inflammasome signaling, interleukin-1 $\beta$ production, and the host immune response to infection. Crit Care Med 46: e1183-e1189, 2018.

9. Liang S, Cai J, Li Y and Yang R: 1,25-Dihydroxy-Vitamin D3 induces macrophage polarization to $\mathrm{M} 2$ by upregulating T-cell Ig-mucin-3 expression. Mol Med Rep 19: 3707-3713, 2019.

10. Chistiakov DA, Killingsworth MC, Myasoedova VA, Orekhov AN and Bobryshev YV: CD68/macrosialin: Not just a histochemical marker. Lab Invest 97: 4-13, 2016.

11. Ooshima A, Park J and Kim SJ: Phosphorylation status at Smad3 linker region modulates transforming growth factor- $\beta$-induced epithelial-mesenchymal transition and cancer progression. Cancer Sci 110: 481-488, 2019.

12. Shi Q and Chen YG: The functional switch of TGF- $\beta$ signaling in breast cancer. Oncotarget 10: 1604-1605, 2019.

13. Trajceska L, Severova-Andreevska G, Dzekova-Vidimliski P, Nikolov I, Selim G, Spasovski G, Rambabova-Busletik I, Ristovska V, Grcevska L, Grcevska L and Sikole A: Complica-tions and risks of percutaneous renal biopsy. Open Access Maced J Med Sci 7: 992-995, 2019.

14. Rakaee M, Busund LR, Jamaly S, Paulsen EE, Richardsen E, Andersen S, Al-Saad S, Bremnes RM, Donnem T and Kilvaer TK: Prognostic value of macrophage phenotypes in resectable non-small cell lung cancer assessed by multiplex immunohisto-chemistry. Neoplasia 21: 282-293, 2019.

15. Doi K, Nishida O, Shigematsu T, Sadahiro T, Itami N, Iseki K, Yuzawa Y, Okada H, Koya D, Kiyomoto H, et al: The Japanese clinical practice guideline for acute kidney injury 2016. Clin Exp Nephrol 22: 985-1045, 2018.
16. Nester CM and Falk RJ: Introduction: Glomerular disease update for the clinician. Clin J Am Soc Nephrol 11: 1662-1663, 2016

17. Ishigami J and Matsushita K: Clinical epidemiology of infectious disease among patients with chronic kidney disease. Clin Exp Nephrol 23: 437-447, 2019.

18. Conley SM, Abais JM, Boini KM and Li PL: Inflammasome activation in chronic glomerular diseases. Curr Drug Targets 18: 1019-1029, 2017.

19. Noris M and Remuzzi G: Glomerular diseases dependent on complement activation, including atypical hemolytic uremic syndrome, membranoproliferative glomerulonephritis, and C3 glomerulopathy: Core curriculum 2015. Am J Kidney Dis 66: 359-375, 2015.

20. Moledina DG, Cheung B, Kukova L, Luciano RL, Peixoto AJ, Wilson FP, Alfano S and Parikh CR: A survey of patient attitudes toward participation in biopsy-based kidney research. Kidney Int Rep 3: 412-416, 2017.

21. Wang L, Zhang C, Zhang Z, Han B, Shen Z, Li L, Liu S, Zhao X, Ye $\mathrm{F}$ and Zhang Y: Specific clinical and immune features of CD68 in glioma via 1,024 samples. Cancer Manag Res 10: 6409-6419, 2018.

22. Li Z, Maeda D, Yoshida M, Umakoshi M, Nanjo H, Shiraishi K, Saito M, Kohno T, Konno H, Saito H, et al: The intratumoral distribution influences the prognostic impact of CD68-and CD204-positive macrophages in non-small cell lung cancer. Lung Cancer 123: 127-135, 2018.

23. Ngoh CLY, Wee BBK and Wong WK: Lumbar Artery bleed as a complication of percutaneous renal biopsy and a proposed workflow for massive bleeding. Case Rep Nephrol Dial 8: 268-276, 2018.

24. Dias CB, Malafronte P, Lee J, Resende A, Jorge L, Pinheiro CC, Malheiros D and Woronik V: Role of renal expression of CD68 in the long-term prognosis of proliferative lupus nephritis. J Nephrol 30: 87-94, 2017.

25. Guillén-Gómez E, Dasilva I, Silva I, Arce Y, Facundo C, Ars E, Breda A, Ortiz A, Guirado L, Ballarín JA, et al: Early macrophage infiltration and sustained inflammation in kidneys from deceased donors are associated with long-term renal function. Am J Transplant 17: 733-743, 2017.

26. Kang JH, Jung MY, Yin X, Andrianifahanana M, Hernandez DM and Leof EB: Cell-penetrating peptides selectively targeting SMAD3 inhibit profibrotic TGF- $\beta$ signaling. J Clin Invest 127: 2541-2554, 2017.

27. Zeng F, Miyazawa T, Kloepfer LA and Harris RC: ErbB4 deletion accelerates renal fibrosis following renal injury. Am J Physiol Renal Physiol 314: F773-F787, 2018.

28. Hu HH, Chen DQ, Wang YN, Feng YL, Cao G, Vaziri ND and Zhao YY: New insights into TGF- $\beta /$ Smad signaling in tissue fibrosis. Chem Biol Interact 292: 76-83, 2018.

29. Fukuda A,Minakawa A, Sato Y, Iwakiri T, Iwatsubo S, Komatsu H, Kikuchi M, Kitamura K, Wiggins RC and Fujimoto S: Urinary podocyte and TGF- $\beta 1$ mRNA as markers for disease activity and progression in anti-glomerular basement membrane nephritis. Nephrol Dial Transplant 32: 1818-1830, 2017.

30. Ostermann M and Joannidis M: Acute kidney injury 2016: Diagnosis and diagnostic workup. Crit Care 20: 299, 2016.

31. Mehta T, Buzkova P, Kizer JR, Djousse L, Chonchol M, Mukamal KJ, Shlipak M, Ix JH and Jalal D: Higher plasma transforming growth factor (TGF)- $\beta$ is associated with kidney disease in older community dwelling adults. BMC Nephrol 18: 98, 2017.

(i) $($ ) This work is licensed under a Creative Commons Attribution-NonCommercial-NoDerivatives 4.0 International (CC BY-NC-ND 4.0) License. 